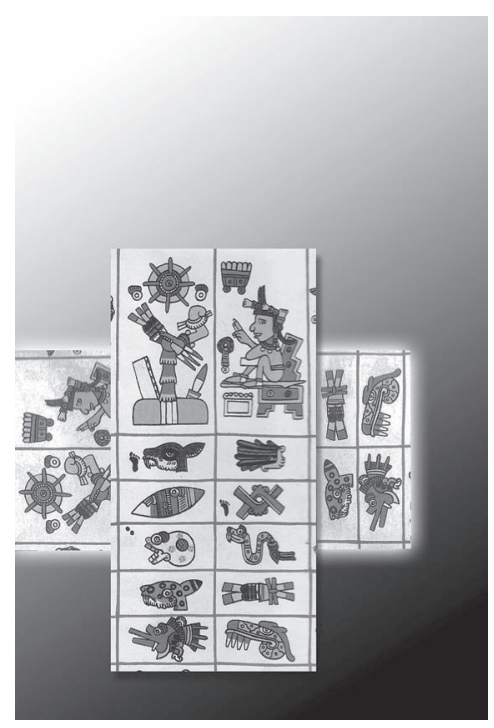




\title{
PLATÃO CONTRA AS PRETENSÕES EDUCATIVAS DA POESIA HOMÉRICA
}

\author{
Lidia Maria Rodrigo*
}

\begin{abstract}
RESUMO: Este artigo procura rediscutir a crítica platônica à poesia de Homero, sustentando a tese de que tal debate é mais pertinente à filosofia da educação do que à teoria da arte, ao contrário do que por vezes se supõe. O afrontamento de Platão à tradição educativa da poesia, tão solidamente instalada na cultura grega, justifica-se acima de tudo pelas exigências inerentes à educação da alma, tal como a concebe o autor. Desse modo, em lugar de uma "teoria platônica da arte", parece mais pertinente falar numa "teoria platônica da educação", na qual a arte ocupa um lugar importante. A reconstituição da argumentação de Platão em relação ao tema baseia-se nos Livros III e $\mathrm{X}$ da República.
\end{abstract}

Palavras-chave: Platão. Poesia homérica. Educação grega.

\section{Plato against the educational PRETENSIONS OF HOMERIC POETRY}

ABSTRACT: This paper discusses anew Plato's criticism to Homer's poetry based on the thesis that, contrary to what is supposed, this discussion is more pertinent to education philosophy than to art theory. Plato's opposition to the educative tradition of poetry - so firmly established in the Greek culture - is above all justified by the requirements of soul education as this philosopher conceived it. Thus, it seems to be more suitable to speak of a "Platonic education theory" in which art occupies an important place than of a "Platonic art theory". Reconstruction of Plato's argumentation is based on The Republic, books III and X.

Key words: Plato. Homeric poetry. Greek education.

\footnotetext{
* Professora do Departamento de Filosofia e História da Educação, da Faculdade de Educação
} da Universidade Estadual de Campinas (UNICAMP).E-mail: lidia@lexxa.com.br 
Platão contra as pretensões educativas da poesia homérica

\section{Sentido histórico do questionamento platônico}

A crítica de Platão à poesia homérica, particularmente nos termos em que aparece sistematizada nos Livros III e X da República, parece sensibilizar de modo muito especial os estudiosos da literatura, o que é compreensível, considerando que tal ataque é endereçado ao autor e à obra identificados com o nascimento da literatura ocidental. Tal enfoque pode conduzir à suposição de que o embate desse filósofo com Homero se processaria no âmbito de uma "teoria da arte" platônica. Penso haver elementos suficientes, tanto no texto do autor como em alguns de seus estudiosos mais respeitáveis, para sustentar a tese de que o debate platônico sobre a poesia é mais pertinente à filosofia da educação do que à teoria da arte.

A imbricação entre educação e poesia é enfatizada com muita insistência por Werner Jaeger na Paidéia, onde postula, por um lado, que a "literatura" grega clássica eleva-se "acima da esfera do puramente estético, onde a quiseram em vão encerrar (...)" (1986, p. 12) e, por outro, que "a história da educação grega coincide substancialmente com a da literatura” (ibid., p. 13). Nessa mesma perspectiva, Susan Levin (2001, p. 152) refere-se ao papel tradicional da poesia como núcleo ou essência da pedagogia. Julia Annas (1994, p. 122) considera que o tratamento que Platão confere à poesia resultou mais numa teorização sobre o lugar que esta deve ocupar na educação do que numa teoria sobre o lugar das artes em geral. Eric Havelock (1996, p. 44) vai mais além, assegurando que a poesia constitui o cerne da teoria educacional de Platão. Parece ser mais pertinente, portanto, em lugar de uma "teoria platônica da arte", falar de uma "teoria platônica da educação", na qual a arte ocupa um lugar importante.

Além do mais, a redução do confronto entre Platão e a poesia a uma discussão de âmbito literário conduz a certas dificuldades interpretativas e torna difícil encontrar respostas para determinadas questões como, por exemplo: Por que Platão, reconhecidamente, como todo grego, um apaixonado pela poesia, a desqualifica a ponto de expulsar o poeta de sua cidade ideal?

$\mathrm{Na}$ análise do discurso platônico sobre Homero, não se pode isolar o embate com a poesia do contexto mais amplo em que ele se processa e a partir do qual se explicitam suas motivações que, do meu pon- 
to de vista, não são prioritariamente estéticas. Também parece completamente anacrônico refutar o questionamento de Platão invocando os direitos do imaginário e do ficcional contra o imperialismo da razão, direitos que, afinal de contas, só puderam ser reivindicados com base em concepções estéticas e literárias formuladas muitos séculos depois de Platão.

A esse respeito, parece significativo que no Livro II da República o exame crítico da poesia seja desencadeado num contexto em que o que está em pauta é uma questão educativa e não uma questão estética. Como educar os guardiōes? Platão se propõe a seguir a via trilhada pela educação tradicional - a ginástica para o corpo e a música para a alma (cf. 376e) -, embora rompendo com o modo tradicional de conceber esta última. A música como meio de educação da alma, eis o que leva Platão a aproximar-se da poesia no texto da República.

A poesia dotada de função educativa, uma idéia tão estranha ao nosso mundo, exprimia uma visão bem própria e há muito consagrada na cultura grega. O mote de "Homero, educador da Hélade", que Platão e muitos outros repetem, exprime, na verdade, um senso comum sobre aquele que era considerado o maior de todos os poetas.

Sabe-se que a oralidade constituiu a marca da cultura grega antiga, e não apenas no seu passado mais remoto. Embora na primeira metade do século IV a.C. a alfabetização já estivesse razoavelmente disseminada entre a população, as formas orais continuavam predominando na comunicação de modo geral. Como lembra Finley (1984, p. 82), os gregos preferiam falar e ouvir. Ora, mas toda sociedade caracterizada pela oralidade tem de encontrar alguma solução para a questão da preservação de sua tradição cultural. Como conservar a memória dos feitos e realizaçôes que lhe conferem identidade, garantindo, por um lado, sua transmissão de geração a geração e, por outro, resguardando-a o máximo possível de deformaçóes subjetivas, de modo a manter regular e constante a tradição? Obviamente, a fala ritmada da poesia se presta muito melhor do que a prosa para garantir a conservação e fixidez na transmissão oral.

Depositário da memória social e instrumento de educação das novas gerações, o enredo poético era permeado por conhecimentos úteis e prescrições sobre os mais diversos aspectos da vida social: éticos, políticos, históricos, hábitos e costumes, rituais diversos e até mesmo conhecimentos técnicos. A oralidade marcou profundamente a própria 
Platão contra as pretensões educativas da poesia homérica

produção poética; as obras de Homero, os primeiros poemas escritos não eram para serem lidos, mas declamados. A educação dos cidadãos se fazia ouvindo e memorizado trechos, principalmente da Ilíada e da Odisséia, que eram recitados tanto de modo privado por parte dos pais e anciãos nos rituais familiares, como em locais públicos, teatros ou praças, quando a declamação era feita por profissionais - poetas ou rapsodos. Afinal, a eficácia da poesia como instrumento educativo dependia da recitação constante e reiterada, única forma de preservar do esquecimento aquela tradição cultural.

Ao enumerar as pretensóes educativas da poesia no Livro $\mathrm{X}$ da República, Platão está, portanto, reportando-se a uma concepção tradicional e refletindo uma opinião que se cristalizara na Grécia clássica: "Temos então a considerar, depois disto, a tragédia e Homero, que é seu pai. Certas pessoas dizem que os poetas trágicos conhecem todos os ofícios, todas as coisas humanas referentes à virtude e ao vício e até mesmo as coisas divinas" (598d-e). ${ }^{1}$ Assim, no texto homérico, a função estética - divertir e comover os homens através do que se diz - torna-se indissociável de sua função educativa: as ações, atitudes e procedimentos típicos que ele registra, freqüentemente convertem-se em paradigmas gerais; para além de meras descriçōes, o relato se processa sob a forma de um conjunto de recomendações e prescrições.

Isso não quer dizer que a Ilíada e a Odisséía tenham sido concebidas com a função prioritária de educar. Até mesmo Eric Havelock (1996, p. 79), que faz a opção metodológica de abordar Homero como um autor didático, reconhece que os elementos didáticos ou enciclopédicos contidos na sua obra são secundários em relação aos objetivos do poema épico e provavelmente constituem um estorvo para a narrativa. Esse estudioso acaba por reconhecer que o poeta é didático, em grande parte de modo inconsciente e que, mesmo nos poetas em que por vezes esse objetivo se revela de forma um pouco mais consciente, "sua capacidade de dar prazer tem prioridade sobre seu dever de instruir" (ibid., p. 102, nota 2).

De qualquer modo, e independentemente das intençôes dos poetas, ao longo do tempo foi se cristalizando entre os gregos a opinião que via na poesia uma função educativa, percepção comum não só entre a população, mas também compartilhada por alguns filósofos desde o período arcaico. 
Tanto a referência a Homero como educador de toda a Grécia, como a censura ao tratamento que ele conferia aos deuses e heróis, tem por trás de si uma tradição muito anterior a Platão. Xenófanes já reconhecia que, "desde o início, todos aprenderam seguindo Homero" (1973, p. 70, Frag. 10), reconhecimento que não o impede de criticar o conteúdo de tais ensinamentos: "Tudo aos deuses atribuíram Homero e Hesíodo, tudo quanto entre os homens merece repulsa e censura, roubo, adultério e fraude mútua" (1973, p. 70, Frag. 11). Heráclito censura Homero em termos ainda mais ásperos: "Homero merecia ser expulso dos certames e açoitado, e Arquíloco igualmente" (1973, p. 89, Frag. 42).

Quando no Livro X da República Platão se refere aos que louvam Homero, "dizendo que esse poeta foi o educador da Grécia, e que é digno de se tomar por modelo no que se refere à administração e à educação humana, para aprender com ele a regular toda a nossa vida (...)" (606e), registra, por um lado, uma percepção que já gozava de consenso e, por outro, assinala o aspecto que ele próprio priorizará em sua análise do texto homérico.

Embora se possa supor que a indagação platônica sobre o conteúdo moral da poesia seja autorizada pelas pretensões educativas que lhe eram inerentes e ainda vigentes na época de Platão, como se mostrou acima, não resta dúvida, entretanto, quanto à audácia de tal questionamento. Talvez seja importante perguntar: Como se tornou possível o afrontamento à tradição educativa da poesia, tão solidamente instalada na cultura grega?

Algumas condições históricas contribuíram para tornar possível o questionamento de Platão, especialmente o processo de laicização da palavra. Na Grécia arcaica (séc. VIII a VI a.C.), havia predominado a palavra poética de inspiração divina, considerada imediatamente veiculadora da verdade (alétheia), uma vez que seu estatuto não dependia de nenhuma exigência de demonstração, nem estava submetido a qualquer contestação. Situando-se num universo mítico-religioso, a palavra do poeta não podia ser posta em questão (Detienne, s/d, p. 15-18).

O quadro social e político que se instaura posteriormente no período clássico, inclusive com o advento da polis, produz modificações substanciais em relação à situação anterior. Como mostra Vernant (1990, p. 380), as regras do jogo político - isto é, a livre discussão e 
Platão contra as pretensões educativas da poesia homérica

o debate a partir de argumentações contrárias - contribuem para a instauração de um novo registro da palavra também no campo intelectual, abrindo assim a possibilidade do questionamento da palavra poética, algo impensável no período arcaico.

No contexto da polis democrática, em que o poeta perde seu caráter sagrado em meio ao processo de laicizaçáo da palavra, no qual toda opiniāo está sujeita à discussão, há condições históricas muito mais favoráveis do que no período anterior para que Platão coloque em xeque o lugar que a tradição grega reservava à poesia: o de principal representante de toda a paidéia. Não se pode perder de vista que tal contestação pretende, simultaneamente, atribuir à filosofia competência para definir uma forma mais elevada de educação do homem. Como assinala Jaeger (1986, p. 670), "o debate entre a Filosofia e a poesia tem necessariamente de recrudescer no momento em que a Filosofia ganha consciência de si própria como paidéia e, por sua vez, reivindica para si o primado da educação".

Nesse novo quadro político e cultural, movido pela intenção de conferir à filosofia um lugar privilegiado entre as potências educativas do seu tempo, basicamente a poesia e a sofística, Platão parece julgar-se no direito de indagar se o discurso poético contém algum saber verdadeiro.

\section{A dissociação platônica entre a dimensão estética e o conteúdo moral} da poesia: quebrando o encanto

Uma das razões pela qual se torna impossível defender os poetas das críticas de Platão, em nome da autonomia estética da arte, reside na não separação entre estética e ética característica da cultura grega. Nas obras de Homero, esses dois aspectos são claramente indissociáveis: valores e normas de comportamento exprimem-se encarnados em heróis e eventos que encantam e divertem. A expressão artística de valores e conteúdos normativos contribui para potencializar seu poder de influência sobre os homens em razão da força emocional de que é dotada essa forma de expressão.

A originalidade da crítica platônica reside precisamente em dissociar, para efeito de análise, a dimensão estética e o conteúdo moral da poesia homérica e, mais do que isso, detectar a possibilidade de 
que entrem em contradição. Distanciando-se do modo habitual de contemplar a poesia, inclusive no seu tempo - o ponto de vista do agradável -, Platão se propõe a analisá-la de outra perspectiva, a do seu caráter ético-educativo, constatando haver, muitas vezes, flagrante conflito entre o ideal estético e o conteúdo moral.

Tal contradição é apontada em várias passagens da Ilíada e da Odisséía, citadas nos Livros II e III da República, tendo com parâmetro a teoria das virtudes cardeais. As referências atemorizantes ao Hades atentam contra a coragem (thymós); mençôes indignas e desrespeitosas aos deuses depóem contra a piedade; a descrição dos heróis em posturas e comportamentos condescendentes em relação à bebida, à comida e ao sexo peca do ponto de vista do desenvolvimento da temperança (sophrosýne). A seqüência de citaçôes das obras de Homero em que se verificam tais exemplos, antagônicos aos princípios que deveriam orientar a educação dos guardiões, leva Platão (387b) a concluir:

Palavras como estas e outras da mesma espécie, pediremos a Homero e aos outros poetas, para que não se agastem se as apagarmos, não que não sejam poéticas e não agradem aos ouvidos da maioria; mas quanto mais poéticas, menos convém que sejam ouvidas por crianças e por homens que devem ser livres, e temer a escravidão mais do que a morte.

Note-se que Platão não duvida do encanto e do prazer estético propiciados pelas cenas homéricas referidas, nem que elas sejam responsáveis pelo valor artístico da poesia, tornando-a mais agradável. Mas Homero pode levar uma pessoa a desviar-se do reto caminho, e essa é a razão fundamental pela qual, ainda que a poesia de fato proporcione prazer, Homero deve ser censurado.

Fica estabelecida, desse modo, a possibilidade de um conflito entre o prazer artístico e a missão educacional da poesia. E, sendo esse o caso, quanto mais atraente for a poesia do ponto de vista artístico, tanto mais perigosa ela se torna do ponto de vista ético-educativo, pois, como lembra Jaeger (1986, p. 538, nota 80), quanto mais intenso é o prazer, maior é a eficácia formativa de uma obra de arte sobre quem a contempla, particularmente entre os gregos, em que a capacidade de prazer estético alcançou um grau mais elevado do que em qualquer outro povo.

A famosa passagem do Livro III (397e a 398b) em que Platão expulsa de sua cidade ideal o poeta imitador, aceitando, contudo, o 
Platão contra as pretensões educativas da poesia homérica

poeta "narrador de histórias mais austero e menos aprazível", pode ser compreendida a partir do conflito entre o prazer e o bem. O que se pretende banir é a criação poética que visa sobretudo agradar, mesmo que à custa daquilo que é benéfico para o indivíduo e para a cidade. A opção pelo "narrador austero" justifica-se "tendo em conta a sua utilidade, a fim de que ele imite para nós a fala do homem de bem" (398b).

Por outro lado, sob a ótica platônica, certos recursos estéticos, como a fala ritmada, que tornam a poesia tão sedutora, não cumprem apenas a função de embelezá-la. Tais recursos podem ser instrumentalizados numa outra direção, ou seja, visando ocultar a precariedade do discurso poético, que graças a tais artifícios consegue ostentar um valor que não possui, aparentando ter conhecimento, quando do conhecimento só possui a aparência.

(...) parece-me que o poeta, por meio de palavras e frases, sabe colorir devidamente cada uma das artes, sem entender delas mais do que saber imitá-las, de modo que, a outros que, como ele, só julgam pelas palavras, parece falar muito bem, quando disserta sobre a arte de fazer sapatos, ou sobre a arte da estratégia, ou sobre qualquer outra com metro, ritmo e harmonia. (601a)

A beleza da obra poética acaba revelando-se, então, uma beleza apenas aparente, o que basta para convencer a multidão ou aquele que não tem conhecimento suficiente para emitir juízos sobre sua validade. Metro, ritmo e harmonia embelezam a palavra poética, tornando-a atraente e sedutora. Tais recursos se prestam também, na perspectiva platônica, para camuflar sua falta de beleza autêntica. A mesma estética que embeleza e seduz pode ser empregada para ocultar a falta de valor e de beleza real no sentido em que Platão a concebe, pois, segundo o autor, "aquilo que parece belo à multidão e aos ignorantes, é isso mesmo que ele [poeta] imitará" (602b).

Platão está consciente de que os atributos estéticos da poesia agradam à maioria e, desse ponto de vista, reconhece a maestria de Homero, concordando com a opinião geral de que ele é o maior dos poetas (607a). Seu gênio poético está fora de questão, mas apenas dentro de limites estritamente estéticos, visto que, por outro lado, o autor diverge da opinião cristalizada que elevava Homero à categoria de educador do povo grego. 
Sendo inegável a força de atração da poesia e seu poder não apenas de educar as crianças, mas também de influenciar os homens, Platão ainda não se mostra claramente disposto a abrir mão desse recurso educativo, ao menos no âmbito do Livro III. A expulsão do poeta imitador não parece ser definitiva, uma vez que permanece aberta a possibilidade de seu regresso. Mas o retorno da "Musa aprazível", para usar os termos platônicos, à cidade ideal fica condicionado à comprovação da possibilidade de conciliar a beleza da arte poética com sua missão educativa, ou seja, os defensores da poesia devem demonstrar "que ela é não só agradável, como útil para os Estados e a vida humana" (607d).

Mesmo assim, diga-se que, se a poesia imitativa, que tem por objetivo o prazer, tiver argumentos para provar que deve estar presente numa cidade bem ordenada, a receberemos com gosto, pois temos consciência do encantamento que exerce sobre nós; mas seria impiedade trair o que julgamos ser verdadeiro. Ou não te sentes também seduzido pela poesia, meu amigo, sobretudo quando a contemplas através de Homero? (607c-d)

Platão não se revela, por princípio, contrário ao prazer estético. O ideal seria subjugar a força de atração da poesia e subordiná-la aos seus ideais político-educativos. Sem tal sujeição essa força é considerada perigosa (quanto mais agradável menos deve ser ouvida). Em suma, é boa quando se harmoniza com a virtude e má quando entra em conflito com ela. De algum modo, permanece aberta a possibilidade de existir uma boa poesia, capaz de contribuir positivamente para a educação dos homens. A própria censura a certas passagens do texto homérico pode ser interpretada positivamente, visto que deixa implícita a idéia de que, uma vez depurada, torna-se possível resgatar seu potencial educativo.

Mas nada se decide no âmbito do Livro III; enquanto não exibir suas credenciais, a "Musa prazerosa" não será autorizada a entrar na cidade bem ordenada. Se, ao contrário, ficar demonstrada a capacidade dos poetas em promover o bem, eles serão admitidos na polis ideal.

\section{A arte mimética e as partes da alma: razão e paixão}

Embora alguns estudiosos e comentadores de Platão manifestem certa estranheza pelo fato dele voltar ao tema da poesia no Livro $\mathrm{X}$, esse retorno parece plenamente justificado se considerarmos as 
Platão contra as pretensões educativas da poesia homérica

questôes que haviam ficado pendentes ou em aberto no Livro III. Tanto é que o autor começa por lembrar a conclusão estabelecida anteriormente, "não aceitar a parte da poesia de caráter mimético" (595a), acrescentando que se trata agora de tornar ainda mais evidente a necessidade de recusar em absoluto a poesia mimética, como se houvesse continuidade entre a etapa anterior e o novo programa a ser cumprido.

A dificuldade em conciliar as duas perspectivas de análise evidencia-se já pela conotação muito mais ampla que assume o conceito de mimese. Anteriormente, a distinção entre imitativo e não-imitativo se operava no seio da poesia, cujas espécies compreendiam narração, imitação e gênero misto. Portanto, só uma parte da poesia era imitativa, ao passo que, no livro $\mathrm{X}$, a imitação caracteriza a atividade poética enquanto tal e em sua totalidade. Além disso, não apenas a narração era admitida na cidade ideal, mas também a imitação tinha alguma chance de sobrevida, já que sua expulsão não parecia tão definitiva, deixando-se uma porta aberta ao seu regresso, dependendo apenas de que ela provasse ser possível conciliar a beleza da sua arte com sua missão educativa.

Essa questão tem seu desfecho anunciado por Platão logo no início do Livro X: trata-se de banir da cidade ideal toda poesia imitativa. A possibilidade de justificar melhor a necessidade dessa recusa absoluta repousa, segundo o autor, na definição das partes da alma desenvolvida no Livro IV. À luz dessas definiçôes, um novo argumento pode ser levantado: "parece-me que todas as obras desse gênero [miméticas] causam a ruína da alma daqueles que a ouvem, se eles não tiverem o antídoto (phármakon), isto é, o conhecimento daquilo que elas realmente são" (595b). A compreensão de tal argumento demanda o esclarecimento de duas questôes:

1) Por que a poesia mimética causa a ruína da alma daqueles que a ouvem?

2) Em que sentido o conhecimento da verdadeira natureza da mimese pode oferecer um antídoto a esse efeito danoso?

O equacionamento dessas duas questóes deve começar por levar a sério a pista fornecida pelo próprio Platão, isto é, recorrer ao Livro IV, embora com alguns cuidados, uma vez que a consideração das partes da alma se faz de modo um pouco distinto. Como aponta Émile Chambry, na edição da Belles Lettres, no Livro IV (436 e ss.), Platão estabelece a 
existência de três partes na alma: a racional (logistikon), a colérica ou irascível (thymoeides) e a apetitiva ou concupiscível (epithymetikon). No Livro $\mathrm{X}$, ao estabelecer a correspondência entre as artes miméticas e os elementos da alma, ele considera apenas duas partes: a racional (logistikon) e a irracional (alogistikon), na qual ele engloba a irascível e a concupiscível (Chambry, 1982, p. 94-95).

A análise da verdadeira natureza da arte mimética inicia-se pelo exame do conceito geral de mimese, caracterizada como produção de objetos aparentes, desprovidos de existência real (596e). Assim concebida, a arte da imitação vai além da própria poesia, configurando-se como um gênero que, no âmbito do Livro X, compreende duas espécies de produção artística: a pintura e a poesia.

Enquanto detentor de uma arte mimética, o pintor produz apenas imitações das obras dos artífices e, por isso, sua obra está três pontos afastada da realidade (597e), como demonstra Platão, com base no exemplo das camas e mesas. A pintura não consegue ir além da aparência visível do objeto e, mesmo assim, atinge apenas uma pequena parte dessa aparência, isto é, sua aparição segundo determinado ângulo (598b-c).

Além do mais, a exemplo da poesia, os recursos estéticos de que se serve o pintor - as cores, a alteração das proporções e demais aparatos responsáveis pela produção de ilusões de ótica - visam enganar o espectador ingênuo e ignorante, artifícios que procuram conferir às suas produções uma aparência semelhante ao real, criando obstáculos adicionais para que se veja os objetos como realmente são (598c).

A poesia homérica, por sua vez, é reexaminada com base no conceito geral de mimese. Trata-se de averiguar se a opinião geral sobre os poetas, considerados portadores de um saber enciclopédico (598e), corresponde à verdade. A avaliação do conhecimento relativo aos diferentes temas que abordam em suas obras leva Platão a concluir que, a começar por Homero, todos os poetas são imitadores da virtude e de todos os assuntos sobre os quais compõem, permanecendo muito distantes da verdade. Os poetas imitam os seres humanos, mas sua obra revela que eles têm uma compreensão meramente aparente dos assuntos humanos e, embora ofereçam apenas imagens dessas realidades, utilizam-se de recursos artísticos para enganar, simulando uma sabedoria que não possuem (601a). 
Platão contra as pretensões educativas da poesia homérica

Portanto, torna-se possível estabelecer uma analogia entre a pintura e a poesia enquanto artes miméticas: ambas imitam seus assuntos e são ignorantes sobre a verdade da matéria a que se aplicam.

Tanto no caso da pintura como da poesia, o emprego de artifícios artísticos responde pelo grande poder de atração que a arte exerce sobre os homens. Platão deseja saber em que parte do homem a arte da imitação exerce o poder que detém (602c). A reflexão volta-se, então, precisamente para aquele ponto que no início do livro X Platão considerava essencial, no sentido de evidenciar a necessidade de uma ruptura absoluta com a poesia mimética: a relação dessa arte com as partes da alma, discussão que se processa em duas etapas. Na primeira, tratase de examinar a parte da alma que convive com a pintura; na segunda, aquela que convive com a poesia. A analogia entre pintura e poesia se mantém, na medida em que Platão procura equiparar a propensão ao erro dos sentidos com a propensão para a paixão, situando ambas na parte irracional da alma, oposta, portanto, à razão.

Exercendo o seu poder de atração sobre a nossa percepção sensível, a pintura, por meio de artifícios estéticos - cores, sombreados, alteração das proporções do objeto -, produz intencionalmente toda espécie de confusão na nossa alma (602c-d). Tal efeito se torna possível porque ela se aplica àquilo que Platão denomina uma "enfermidade da nossa natureza" (602d). No Livro IV o autor estabelece que o elemento da alma que impele e arrasta o homem para a realização dos desejos, contrária à ação da razão que luta para resistir a eles, deriva de afecçōes mórbidas. Ligando-se a essa parte irracional da alma, a pintura acaba por reforçar e fortalecer nossa sensibilidade enferma, nossas percepçōes distorcidas. Contra os inconvenientes oriundos dessa sensibilidade enferma, que deforma nossa percepção das coisas, os homens inventaram o cálculo e a medida, operações que se tornam possíveis pelo trabalho da razão.

As funçôes contraditórias dessas duas partes da alma produzem efeitos que resultam no surgimento de aparências contraditórias dos mesmos objetos e ao mesmo tempo. Ora, adverte Platão, mas "o que julga na alma à margem da medida, não poderá ser o mesmo que o que julga com medida" (603a). Funções diferentes são desempenhadas por partes diferentes da alma: a que julga racionalmente, com base na medida e no cálculo, é superior e constitui a melhor parte; aquela que 
desempenha a função contrária, quer dizer, julga a partir de uma sensibilidade desregrada, com base em impressões meramente subjetivas sobre as aparências das coisas, é a pior parte. Tais conclusões têm caráter amplo: não apenas a pintura, mas a arte de imitar em geral, "convive com a parte de nós mesmos contrária ao bom-senso, sem ter em vista, nesta companhia e amizade, nada que seja são ou verdadeiro" (603b).

À luz desse princípio, resta ainda examinar a parte da alma que convive com a imitação poética, para saber se ela é inferior ou se possui valor, questão que, nessa altura, poderia ser considerada meramente retórica, não fosse a necessidade de explicitar melhor a imitação poética, assinalando sua especificidade. Sob a ótica de análise que se tornou possível a partir do Livro IV, no qual Platão separa as partes da alma com base na sua dissensão interna, trata-se de saber se nas narrações poéticas o homem age sempre de acordo consigo mesmo ou vive contradiçôes análogas às que foram constatadas no campo da sensibilidade.

Falar em dissensão interna significa dizer que o homem possui dentro da sua alma partes contraditórias que o levam a lutar consigo mesmo: o inimigo não está fora, mas no seu próprio interior. $\mathrm{O}$ inimigo é a parte da alma que se deixa arrastar pelo desejo que, por sua vez, é infinito, insaciável e comum a todos os homens, pois, como nota o autor, todos têm desejo do que é bom (boa comida, boa bebida etc.) (438a). Frente ao desejo, há na alma dois elementos: um que impele e outro que resiste à realização dos desejos. $\mathrm{O}$ elemento que resiste provém do raciocínio, o que impele e arrasta a alma deriva das impressōes recebidas e das afecções mórbidas (439c-d).

As virtudes se estabelecem precisamente a partir do trabalho do elemento racional da nossa alma, cujo triunfo consiste em manter sob seu domínio certos prazeres e desejos. Uma ilustração interessante da noção de "dissensão interna" aparece na análise de Platão sobre uma expressão de uso corrente: "ser mais forte que si mesmo". Justamente pelo fato de se tratar de uma luta interior, e o inimigo contra o qual se combate estar dentro da própria alma, Platão argumenta que "quem é mais forte que si mesmo será também, sem dúvida, mais fraco que si mesmo, e aquele que é mais fraco, mais forte, considerando que todas estas expressôes se referem à mesma pessoa" (430e-431a). ${ }^{2}$ Para o autor, a expressão "ser mais forte que si mesmo" revela vestígios da temperança, exprimindo a vitória da melhor parte da alma sobre a pior. 
Platão contra as pretensões educativas da poesia homérica

Voltando ao Livro X, trata-se, então, de saber como as narrativas poéticas se relacionam com esses elementos contraditórios da alma humana. Diante dos desgostos e desgraças pessoais, o homem se defronta com a contradição dentro de si: há, por um lado, o impulso de se entregar ao sofrimento e, por outro, o de moderar seu desgosto e manter a calma. Para Platão, a força que impele o homem a resistir é a melhor parte, aquela que segue a razão e a lei, ao passo que a força que o arrasta para a dor é a parte irracional da alma, preguiçosa e propensa à covardia $(604 a-d)$.

É possível, então, responder à questão acima, determinando a parte da alma que convive com a imitação poética e que valor ela tem. A poesia convive com a parte da alma que, segundo Platão, contém material mais adequado à imitação: a parte irascível. Os poetas imitam os seres humanos sob o domínio do amor, da ira e de todas as paixōes penosas ou aprazíveis da alma (606d). Portanto, imitam os piores impulsos da alma humana e contribuem para fortalecer sua parte inferior e desejante, encorajando o homem a entregar-se às suas emoções e sentimentos imediatos, resistindo, assim, à mediação da razão.

Fica claro também porque a poesia mimética causa a ruína da alma dos que a ouvem. Empregando intencionalmente uma linguagem política, Platão considera que a obra poética instaura na alma de cada indivíduo um mau governo, subvertendo a relação hierárquica entre suas partes. No Livro IV tal hierarquia é determinada com precisão: compete à razão governar, uma vez que é sábia e tem o encargo de velar pela alma toda, ao passo que a parte colérica ou irascível deve ser sua súdita e aliada (441e). Os poetas levam seu público a privilegiar as partes da alma que deveriam ser mantidas numa posição subserviente (Pappas, 1995, p. 179). Ao fortalecer a parte irascível e irracional, contribuem para nos distanciar da razão e arruínam nossa alma, tornando difícil administrar nossa vida (605b). O mau governo consiste precisamente em erigir em soberano aquele que deveria ser súdito.

Esclarecida a verdadeira natureza da mimese, resta saber em que sentido tal conhecimento pode oferecer um antídoto aos efeitos danosos da poesia. Platão considera que o efeito mais funesto da poesia reside no seu poder de influenciar inclusive as pessoas honestas, aquelas que conseguem manter sob controle da razão suas próprias paixóes, mas que, por desconhecerem a verdadeira natureza da mimese, acreditam 
não ser necessário privar-se do prazer da poesia, julgando que não serão afetadas por ela, uma vez que estão contemplando paixões alheias. Poucos se dão conta, segundo o autor, que se entregar à contemplação da livre manifestação do sentimento alheio e sofrer com ele, mesmo que seja através da representação, reforça nossa parte passional, tornando difícil depois conter as próprias paixões $(606 \mathrm{a}-\mathrm{b}) .^{3}$ Isso pode ocorrer quando "a parte de nós que é a melhor por natureza, por não estar suficientemente educada pela razão e pelo hábito, abranda a vigilância dessa parte dada às lamentações (...)" (606a).

A parte irascível pode ser auxiliar da parte racional, a menos que, adverte Platão, ela tenha sido corrompida por uma má educação (441a). Sob a ação de uma boa educação, quando as paixões impelem o homem a agir contra a razão, ele se censura e se irrita contra aquilo que o força, como se dentro dele houvesse dois contendores em luta (440a-b). Nesse caso, a cólera ou elemento irascível converte-se em aliado da razão.

Assim, pela educação a razão pode dominar a parte passional, mas a vigilância deve ser constante para que a parte inferior, alimentada pelos prazeres, não se torne mais forte e domine a parte racional, subvertendo a ordem natural da alma (cf. 441e-442b). A educação da alma por meio da poesia, precisamente por fortalecer e privilegiar a parte irascível, promove esse tipo de subversão.

Evidencia-se, portanto, a razão pela qual é preciso romper em absoluto com a poesia mimética e, em relação ao poeta, fechar definitivamente a porta que havia ficado entreaberta para o seu regresso no Livro III. Quase ao final da discussão sobre a poesia no Livro X, Platão concluirá: "Aqui está o que tínhamos a dizer, ao lembrarmos de novo a poesia, por justificadamente excluirmos da cidade uma arte dessa espécie. Era a Razão que a isso nos impelia" (607b).

A exclusão total da poesia em nome da razão remete, inevitavelmente, à dissensão entre filosofia e poesia, duas formas inteiramente diversas de conceber a educação da alma. E Platão a reconhece explicitamente lembrando que é antigo o antagonismo entre a filosofia e a poesia (607b); como prova disso, cita várias expressões ofensivas à filosofia atribuídas aos poetas $(607 \mathrm{~b}-\mathrm{c})$. Ignora-se de onde ele teria retirado tais citações poéticas, ao contrário dos ataques dos filósofos à poesia, devidamente registrados, de forma particular, nos fragmentos de Heráclito e Xenófanes, já referidos anteriormente. 
Platão contra as pretensões educativas da poesia homérica

Embora Platão revele ter consciência de que suas investidas contra a poesia dão seqüência a uma longa tradição, ele vai muito além de seus antecessores. Não se restringe a censurar a influência negativa das narraçôes poéticas na formação do espírito, mas reivindica para a filosofia a missão educativa tradicionalmente atribuída aos poetas, assumindo, na República, o papel de um renovador de toda a paidéia grega (Jaeger, 1986, p. 531). A aparência de saber oferecida pelo ensinamento dos poetas contrapóe a verdade superior da filosofia, elaborada segundo exigências estritamente racionais.

Sabe-se que a intervenção de Platão no debate educativo do seu tempo, procurando estabelecer a hegemonia da filosofia como força educativa, processou-se em duas frentes, visando combater duas rivais com igual pretensão: a poesia e a retórica sofística. A luta contra a retórica travada no Górgias e em outros diálogos não comporta, entretanto, a mesma carga sentimental que se verifica em relação à poesia. Afinal, a afeição e admiração por esta última forma de expressão instalam-se em todo grego ainda na fase infantil, dado o costume de educar as crianças pela poesia. Platão acaba por admitir que a razão deve lutar contra "o amor por essa poesia que em nós se formou por influência da educação dos nossos belos Estados", ou, em outros termos, contra "aquela paixão de nossa infância, que é a da maioria" (608a). A razão justifica a ruptura, mas não a torna menos dolorosa: “(...) faremos como os apaixonados que, reconhecendo os efeitos funestos de sua paixão, afastam-se dela de má vontade, mas, mesmo assim, se afastam" (607e).

Recebido em junho de 2005 e aprovado em março de 2006.

\section{Notas}

1. A tradução das passagens da República citadas neste trabalho, salvo observação em contrário, baseia-se no confronto entre a tradução de Maria Helena da Rocha para a edição da Fundação Calouste Gulbenkian e a tradução de Émile Chambry para a edição Platon: ouvres complètes, da Société D’Èdition "Les Belles Lettres".

2. Citação baseada na tradução de Léon Robin, editada pela Gallimard.

3. Auguste Diès lembra, a propósito, que Platão só vê na simpatia um poder de excitação e de sugestão, diferentemente de Aristóteles, que considerava essencial seu efeito apaziguador e purgativo. Cf. Platon, Oeuvres complètes (Tome VI, Introduction, p. CXV). Paris: Les Belles Lettres, 1981. 
Referências bibliográficas

ACHCAR, F. Platão contra a poesia. Revista USP, São Paulo, n. 8, dez. 1990/fev. 1991.

ANNAS, J. Introduction à la "Republique" de Platon. Paris: puf, 1994.

DETIENNE, M. Os mestres da verdade na Grécia Arcaica. Rio de Janeiro: Zahar, s.d.

GOLDSCHIMIDT, V. Les dialogues de Platon: structure et méthode dialectique. 3. éd. Paris: PUF, 1971.

HAVELOCK, E. Prefácio a Platão. Campinas: Papirus, 1996.

HERÁClITO de Éfeso. In: SouzA, J.C. (Org.). Os pré-socráticos. São Paulo: Abril Cultural, 1973. (Os pensadores).

JAEGER, W. Paidéia: a formação do homem grego. São Paulo: Martins Fontes, 1986.

LEVIN, S.B. The ancient quarrel between philosophy and poetry revisited: Plato and the Greek literary tradition. New York: Oxford University, 2001.

PLATÃO. A República. Trad. de Maria Helena da Rocha Pereira. 7. ed. Lisboa: Calouste Gulbenkian, 1993.

PLATON. Oeuvres complètes. Paris: Belles Lettres, 1981. t. 6

PLATON. Oeuvres complètes. Paris: Belles Lettres, 1982. t. 7, pt. 2.

PLATON. Oeuvres complètes I. Paris: Gallimard, 1984.

VERNANT, J.-P. Mito e pensamento entre os gregos: estudos de psicologia histórica. Rio de Janeiro: Paz \& Terra, 1990.

XENÓFANES de Colofăo. In: SouzA, J.C. (Org.). Os pré-socráticos. São Paulo: Abril Cultural, 1973. (Os pensadores) 